\title{
Apresentação Geral do Ciclo de Premiação 2002
}

\author{
Francine Lemos e Marco Antonio Teixeira \\ (Membros da Equipe de Coordenação do Programa GESTÃO PÚBLICA E CIDADANIA)
}

Em 2002, na sétima edição do seu Ciclo de Premiação, o Programa Gestão Pública e Cidadania, recebeu 981 inscrições válidas, o que significou um incremento de $35 \%$ em relação aos 727 inscritos no ano anterior. Do total de inscrições, 819 (84\%) foram realizadas por municipios, $144(15 \%)$ efetuadas por governos estaduais e $13(1 \%)$ sob a responsabilidade de organizações próprias dos povos indígenas.

O banco de dados do Programa já acumula um total de 5.099 experiências governamentais enviadas por municípios, governos estaduais e organizações próprias dos povos indígenas. Na tabela 1, destaca-se a distribuição dos projetos por nível de governo no período de 1996 a 2002.

\begin{tabular}{|c|c|c|c|c|c|c|c|}
\hline \multirow[t]{2}{*}{ Nivel de Governo } & 1996 & 1997 & 1998 & 1999 & 2000 & 2001 & 2002 \\
\hline & n.a $(\%)$ & n.a $(\%)$ & n.a (\%) & n.a $(\%)$ & n.a $(\%)$ & n.a (\%) & n.a (\%) \\
\hline Estadual & 13421 & 12241 & $224 \quad 35$ & 15718 & 12313 & $97 \quad 13$ & $144 \quad 15$ \\
\hline Municipal & 48878 & 17459 & 40063 & 72181 & 81486 & 62786 & $824 \quad 84$ \\
\hline Indígena & 1 & 0 & 7 & 101 & 1 & 4 & 13 \\
\hline Total & 629100 & 297100 & 631100 & 888100 & 946100 & 728100 & $981 \quad 100$ \\
\hline
\end{tabular}

Verifica-se que as iniciativas realizadas pelos municípios representam a maioria dos projetos inscritos em todos os Ciclos de Premiação. Em 1996, as unidades municipais participaram com $78 \%$ do total de inscrições. No ano de 2002, elas foram responsáveis por $84 \%$ das experiências enviadas ao Programa.

A participação percentual dos projetos enviados pelos governos estaduais apresenta maior oscilação tendo alcançado o melhor patamar, 41\%, no ano de 1997, o primeiro ano após as eleições municipais de 1996 quando a reeleição, neste nível de governo, ainda não era possível ${ }^{1}$.

O maior número de inscrições veio de estados das regiões Sul e Sudeste: São Paulo (305), Minas Gerais (121), Rio Grande do Sul (104), Santa Catarina (86) e Paraná (62). Nessas duas regiões também estão presentes os municípios que mais inscreveram

\footnotetext{
${ }^{1}$ A Emenda Constitucional que possibilitou a reeleição para cargos eletivos do Poder Executivo passou a vigorar no ano de 1998.
} 
projetos em 2002: Porto Alegre (RS), Belo Horizonte (MG), Juiz de Fora (MG), São Paulo $(\mathrm{SP})$, Chapecó (SC) e Mauá (SP).

Ao todo, 290 municípios se inscreveram no Ciclo de Premiação de 2002. Destes, 138 $(47 \%)$ são da região Sudeste, $73(25 \%)$ da região Sul, $47(16 \%)$ da região Nordeste, 19 $(7 \%)$ da região Centro-Oeste e; $13(5 \%)$ da região Norte.

$\mathrm{Na}$ tabela 2, destaca-se a divisão de todos os programas e projetos, por grandes regiões, desde o primeiro Ciclo de Premiação.

\begin{tabular}{|c|c|c|c|c|c|c|c|c|c|c|c|c|c|c|}
\hline \multirow[t]{2}{*}{ Áreas de Governo } & \multicolumn{2}{|c|}{1996} & \multicolumn{2}{|c|}{1997} & \multicolumn{2}{|c|}{1998} & \multicolumn{2}{|c|}{1999} & \multicolumn{2}{|c|}{2000} & \multicolumn{2}{|c|}{2001} & \multicolumn{2}{|c|}{2002} \\
\hline & n.a & $(\%)$ & n.a & $(\%)$ & n.a & $(\%)$ & n.a & (\%) & n.a & $(\%)$ & n.a & (\%) & n.a & $(\%)$ \\
\hline Norte & 17 & 3 & 8 & 3 & 26 & 4 & 38 & 4 & 21 & 2 & 29 & 4 & 45 & 5 \\
\hline Nordeste & 70 & 11 & 61 & 21 & 60 & 10 & 116 & 13 & 121 & 13 & 102 & 14 & 124 & 13 \\
\hline Sudeste & 384 & 61 & 120 & 40 & 324 & 51 & 453 & 51 & 435 & 46 & 357 & 48 & 502 & 51 \\
\hline Sul & 134 & 21 & 62 & 21 & 168 & 27 & 263 & 30 & 333 & 35 & 218 & 29 & 255 & 26 \\
\hline Centro-Oeste & 24 & 4 & 46 & 15 & 53 & 8 & 18 & 2 & 36 & 4 & 22 & 3 & 55 & 6 \\
\hline tal & 62 & & 297 & 100 & 631 & 100 & 888 & 100 & 94 & 1 & 742 & & 1 & 10 \\
\hline
\end{tabular}

Em relação à distribuição dos programas e projetos por grandes áreas geográficas, os dados da tabela 2 deixam claro que as regiões Sudeste e Sul foram as mais presentes nos Ciclos de Premiação, com 82\% das iniciativas enviadas em 1996 e $77 \%$ em 2002. As regiões Nordeste, Centro-Oeste e Norte participaram conjuntamente com $18 \%$ no ano de 1996 e 23\% em 2002.

A distribuição percentual dos projetos por regiões geográficas vem apresentando poucas oscilações no decorrer dos sete anos de existência do Programa. O crescimento do número de inscritos nos Ciclos de Premiação tem ocorrido de maneira uniforme entre as regiões, o que vem contribuindo para que a Região Sudeste se mantenha, em média, com mais de $50 \%$ das iniciativas desde o ano de 1996.

Ao ser analisada a participação proporcional dos municípios por Estado de origem, verifica-se que, diferentemente dos dados anteriores, estados localizados nas regiões menos populosas também se destacam. A tabela 3 traz essa informação, como também mostra um panorama geral sobre a distribuição geográfica de todos os programas e projetos enviados para o Ciclo de Premiação de 2002.

Como pode ser verificado na tabela abaixo, os dados relativos ao número de municípios inscritos em relação ao total de municípios por Estado, revelam que o Rio de Janeiro foi a Unidade da Federação que proporcionalmente possui o maior número de 
cidades inscritas no Ciclo de Premiação de 2002, seguido por São Paulo, Mato Grosso do Sul, Acre, Ceará e Santa Catarina. Ao todo, em 15 estados o nível de participação é de $5 \%$ ou mais.

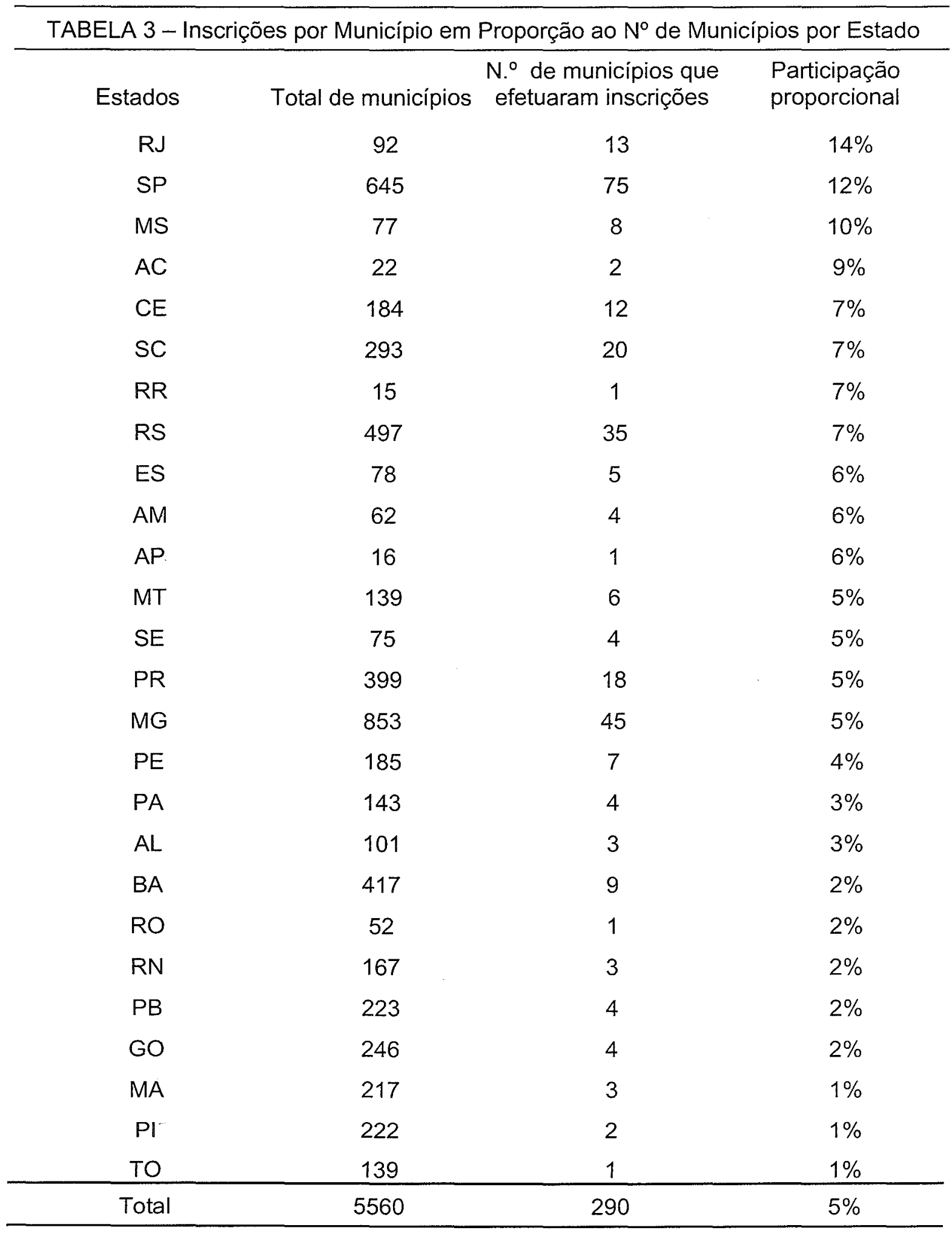


Destaca-se, também, que neste Ciclo de Premiação houve inscrições municipais provenientes de todos os estados da federação, diferentemente de 2001, quando não foi registrada nenhuma inscrição de municípios de cinco estados da Região Norte ${ }^{2}$.

A tabela 4 destaca a presença dos municípios por porte populacional, desde o ano de 1996.

\begin{tabular}{lcccccccc}
\hline \multicolumn{7}{c}{ TABELA 4 - Distribuição Percentual dos Municípios Participantes Segundo No Habitantes } \\
\hline No habitantes & 1996 & 1997 & 1998 & 1999 & 2000 & 2001 & 2002 & IBGE \\
(em milhares) & $(\%)$ & $(\%)$ & $(\%)$ & $(\%)$ & $(\%)$ & $(\%)$ & $(\%)$ & $(\%)$ \\
Até 20 & 25 & 15 & 24 & 30 & 28 & 26 & 23 & 71 \\
20 a 50 & 12 & 18 & 16 & 20 & 17 & 20 & 20 & 19 \\
50 a 100 & 15 & 24 & 19 & 15 & 20 & 18 & 18 & 5,8 \\
100 a 200 & 13 & 16 & 12 & 12 & 11 & 16 & 15 & 2,3 \\
200 a 500 & 19 & 18 & 16 & 12 & 13 & 11 & 14 & 1,4 \\
500 a 1.000 & 8 & 6 & 4 & 4 & 4 & 5 & 4 & 0,3 \\
1.000 a 5.000 & 6 & 3 & 5 & 3 & 3 & 4 & 4 & 0,2 \\
mais de 5.000 & 1 & 1 & 1 & 1 & 1 & 1 & 1 & 0,02 \\
S/ informação. & 0 & 0 & 2 & 2 & 4 & 0 & 0 & 0 \\
& $100 \%$ & $100 \%$ & $100 \%$ & $100 \%$ & $100 \%$ & $100 \%$ & $100 \%$ & $100 \%$ \\
\hline Número Total & 104 & 68 & 146 & 235 & 254 & 176 & 290 & 5560 \\
\hline
\end{tabular}

É possível notar que os municípios com até 20 mil habitantes são os que apresentam maior número de inscrições nos ciclos de premiação do Programa Gestão Pública e Cidadania - 25\% em 1996 e $23 \%$ em 2002. As cidades que se situam na faixa populacional entre 20 e 50 mil moradores também vêm apresentando participação significativa - 12\% em 1996 e $20 \%$ em 2002.

Quanto à participação dos municípios em relação à distribuição nacional de cidades por faixa populacional organizada pelo IBGE, os municípios entre 20 e 50 mil habitantes foram responsáveis por $20 \%$ das inscrições no Ciclo 2002 , o que representa um equilíbrio em relação ao percentual de cidades brasileiras nessa faixa populacional $(19 \%)$. Nesse mesmo Ciclo, os municípios com mais de 50 mil habitantes foram responsáveis por $18 \%$ das inscrições, o que significa uma sobrerepresentação em relação ao percentual de $5,8 \%$ de cidades brasileiras com esse porte populacional.

A presença de municípios com população até 20 mil habitantes entre os inscritos, ainda que em proporção inferior $(23 \%)$ a sua participação no conjunto de municípios do país com este porte populacional $(71 \%)$, constitui um sinal de vitalidade pública nessas

\footnotetext{
${ }^{2}$ Acre, Amazonas, Amapá, Rondônia e Roraima.
} 
localidades que, muitas vezes, são consideradas à margem da vida pública nacional. No Ciclo 2002, recebemos inscrições de programas e projetos de municípios como: Serra da Saudade (MG) - 873 habitantes, Flor do Sertão (SC) - 1.612 habitantes, Tupandi (RS) 2.958 habitantes, São Miguel do Aleixo (SE) - 3.447 habitantes, Japorã (MS) - 6.140 habitantes, entre outros, todos localizados em áreas distantes das principais regiões metropolitanas de seus estados.

As áreas de atuação governamental no ano de 2002 são destacadas na tabela 5.

TABELA 5 - Programas Inscritos em 2002 Segundo as Grandes Áreas de Atuação Governamental

\begin{tabular}{lcc}
\hline \multicolumn{1}{c}{ Áreas de Governo } & n.a & $(\%)$ \\
Serviços públicos & 489 & 50 \\
Cidadania e direitos humanos & 239 & $24-$ \\
Administração e governo & 85 & 9 \\
Desenvolvimento econômico e & & 9 \\
social & 84 & 7 \\
Infra-estrutura e meio ambiente & 71 & 1 \\
Judiciário & 8 & 1 \\
Legislativo & 5 & 100 \\
\hline Total & 981 & \\
\hline
\end{tabular}

Como se verifica na tabela 5 , há uma concentração significativa de programas e projetos na área de Serviços Públicos: $50 \%$ das iniciativas inscritas no Ciclo de Premiação do Programa Gestão Pública e Cidadania em 2002, refletindo o grande peso das demandas nos setores de educação, saúde e assistência social. Em seguida aparece Cidadania e Direitos Humanos com $24 \%$, área na qual se destacam as políticas voltadas para Criança e Adolescente. Apesar de as áreas do Legislativo e do Judiciário terem sido pouco contempladas nesse Ciclo de Premiação, 2002 foi 0 ano em que tais áreas receberam um maior número de inscrições.

A distribuição dos programas inscritos por área de atuação governamental segundo as grandes regióes geográficas, no ano de 2002, pode ser verificada na próxima tabela.

TABELA 6 - Programas Inscritos em 2002, por Área de Atuação Governamental, Segundo a Região Geográfica

\begin{tabular}{lccccccccccc}
\hline \multicolumn{1}{c}{ Área } & \multicolumn{3}{c}{ NO } & \multicolumn{3}{c}{ CO } & \multicolumn{3}{c}{ SE } & \multicolumn{3}{c}{ S } & \multicolumn{2}{c}{ NE } \\
& n.a & $\%$ & n.a & $\%$ & n.a & $\%$ & n.a & $\%$ & n.a & $\%$ \\
Administração e Governo & 2 & 4 & 3 & 5 & 35 & 7 & 19 & 7 & 12 & 10 \\
Infra-Estrutura e Meio Ambiente & 2 & 4 & 2 & 4 & 46 & 9 & 26 & 10 & 9 & 7 \\
Serviços Públicos & 10 & 22 & 30 & 55 & 253 & 50 & 133 & 52 & 63 & 51 \\
Cidadania e Direitos Humanos & 19 & 42 & 14 & 25 & 131 & 26 & 51 & 20 & 24 & 19 \\
Desenvolvimento Econômico e Social & 10 & 22 & 6 & 11 & 27 & 5 & 25 & 10 & 16 & 13 \\
Legislativo & 0 & 0 & 0 & 0 & 8 & 2 & 0 & 0 & 0 & 0 \\
Judiciário & 2 & 4 & 0 & 0 & 2 & 0 & 1 & 0 & 0 & 0 \\
\hline Total & 45 & 100 & 55 & 100 & 502 & 100 & 255 & 100 & 124 & 100 \\
\hline
\end{tabular}


Constata-se que a concentração em Serviços Públicos ocorre na região Centro-Oeste, $55 \%$ das iniciativas; na Sudeste, $50 \%$; na região Sul, $52 \%$; e na Nordeste, $51 \%$.

Na região Norte, as iniciativas inscritas são, em sua maior parte, da área de Cidadania e Direitos Humanos (42\%), seguida pelas áreas de Desenvolvimento Econômico e Social e Serviços Públicos, ambas com $22 \%$, invertendo a ordem verificada nas demais regiões. A presença significativa de programas na área de Cidadania e Direitos Humanos está vinculada a iniciativas de Erradicação do Trabalho Infantil e de proteção a Criança e Adolescente em situação de Risco Social.

Os programas e projetos na área de Infra-estrutura e Meio Ambiente, estão mais presentes na região Sul com $26 \%$ das inscrições, enquanto a área de Desenvolvimento Econômico e Social ganha destaque na região Norte com $22 \%$. As iniciativas nos setores do Judiciário e do Legislativo tiveram participação residual em todas as regiões.

Conclui-se que há uma intensa busca por maior eficiência e transparência dos Serviços Públicos em todas as regiões geográficas, com exceção da região Norte onde se verifica maior presença das iniciativas na área de Cidadania e Direitos Humanos.

Também é interessante notar que apenas as regiões mais industrializadas do país Sudeste e Sul - apresentam índices significativos de programas e projetos na área de Infra-estrutura e Meio Ambiente, $9 \%$ e 10\% respectivamente. Nas regiões Centro-Oeste e Norte - que concentram a maior parte da biodiversidade brasileira - a presença de iniciativas nessa área é bem reduzida: $5 \%$ e $4 \%$. 
Na tabela 7 destacam-se os dados gerais acerca das subáreas que mais foram contempladas dentro de cada uma das áreas de ação governamental.

\begin{tabular}{|c|c|}
\hline \multicolumn{2}{|c|}{$\begin{array}{c}\text { TABELA } 7 \text { - Programas Inscritos em } 2002 \text { Segund` as Subáreas de Atuação } \\
\text { Governamental }\end{array}$} \\
\hline Subárea & $(\%)$ \\
\hline Educação & 18,7 \\
\hline Criança e Adolescente & 13,0 \\
\hline Saúde & 11,2 \\
\hline Assistência Social & 8,1 \\
\hline Patrimônio Público & 7,6 \\
\hline Formação de mão-de-obra, geração de emprego e renda & 4,0 \\
\hline Cultura, patrimônio histórico e artístico & 3,4 \\
\hline Lazer e esportes & 3,1 \\
\hline Deficiente & 2,9 \\
\hline Legislativo & 2,5 \\
\hline Desenvolvimento local e regional & 2,2 \\
\hline Formas de Gestão e Planejamento & 2,0 \\
\hline Idoso & 1,9 \\
\hline Limpeza Pública, coleta, tratamento e destinação final do Lixo & 1,9 \\
\hline Saneamento (água e esgoto) & 1,9 \\
\hline Participação Popular & 1,8 \\
\hline Habitação & 1,5 \\
\hline Relações Intragovernamentais & 0,9 \\
\hline Mulher & 0,8 \\
\hline Sist. de Informação & 0,8 \\
\hline Desenv. E Adm. Pessoal & 0,8 \\
\hline Melhoria da Condições e das Relações de Trabalho & 0,6 \\
\hline Segurança Pública e Policiamento & 0,5 \\
\hline Recursos Hídricos, Irrigação e Drenagem & 0,5 \\
\hline Transporte Público & 0,5 \\
\hline Minorias & 0,4 \\
\hline Sist. de Fiscalização e Controle & 0,4 \\
\hline Trânsito e Vias Públicas & 0,4 \\
\hline Controle da Poluição & 0,4 \\
\hline Ciência e Tecnologia & 0,4 \\
\hline Judiciário & 0,3 \\
\hline Urbanismo, Uso e Ocupação do Solo & 0,2 \\
\hline Consumidor & 0,2 \\
\hline Prevenção de Acidentes em Áreas de Risco & 0,2 \\
\hline Outros & 3,7 \\
\hline Total & 100 \\
\hline
\end{tabular}


Nessa tabela, podemos constatar que as subáreas de Educação, Saúde e Assistência Social, todas incluídas na área de Serviço Público, responderam por $38 \%$ de todos os programas e projetos inscritos. A subárea Criança e Adolescente, parte componente da área de Cidadania e Direitos Humanos foi responsável por $13 \%$ das inscrições. Com isso, verifica-se que essas quatro subáreas, conjuntamente, responderam por $51 \%$ das iniciativas inscritas no Ciclo de Premiação 2002.

$\mathrm{Na}$ tabela seguinte, tratamos da dimensão política identificando os partidos a que pertencem os prefeitos dos municípios que se inscreveram no Ciclo de Premiação 2002.

TABELA 8 - Partidos dos Prefeitos de Municípios que Participaram do Ciclo de Premiação 2002

\begin{tabular}{|c|c|c|c|}
\hline Partido & $\begin{array}{c}\text { No Prefeituras } \\
\text { Inscritas no Ciclo } \\
2002\end{array}$ & $\begin{array}{l}\text { No Prefeituras sob } \\
\text { Responsabilidade do } \\
\text { Partido no País }\end{array}$ & $\begin{array}{c}\text { Relação } N^{\circ} \text { Inscritos / } \\
N^{\circ} \text { no País }\end{array}$ \\
\hline PSDB & 53 & 990 & $5 \%$ \\
\hline PMDB & 51 & 1257 & $4 \%$ \\
\hline $\mathrm{PT}$ & 40 & 187 & $21 \%$ \\
\hline PFL & 40 & 1028 & $4 \%$ \\
\hline PPB & 25 & 618 & $4 \%$ \\
\hline PTB & 19 & 398 & $5 \%$ \\
\hline PDT & 16 & 288 & $6 \%$ \\
\hline PPS & 13 & 166 & $8 \%$ \\
\hline PSB & 12 & 133 & $9 \%$ \\
\hline PL & 10 & 234 & $4 \%$ \\
\hline PSDB & 6 & 111 & $5 \%$ \\
\hline Outros & 5 & 150 & $3 \%$ \\
\hline Total & 290 & 5560 & $5 \%$ \\
\hline
\end{tabular}

(1) os atuais prefeitos foram eleitos no ano 2000.

Os dados da tabela 8 revelam que os 290 municípios inscritos no Ciclo de Premiação 2002 estão sendo administrados pelos mais diversos partidos que compõem a estrutura política brasileira. Isso revela que o Programa Gestão Pública e Cidadania vem conseguindo dialogar com os diversos segmentos políticos que estão à frente da administração pública subnacional.

Os dados proporcionais revelam que apesar de o material de divulgação do Programa Gestão Pública e Cidadania ter sido enviado para o comando de todos os partidos, foram os de centro-esquerda que demonstraram maior sensibilidade para estimular seus prefeitos a participar desse Ciclo de Premiação. Assim, conforme podemos observar na tabela acima, apesar de controlar apenas 187 (3\%) das 5560 prefeituras brasileiras, o PT participou do Programa Gestão Pública e Cidadania com a inscrição de $21 \%$ das cidades administradas pelo partido. 
Em termos quantitativos, as cidades administradas pelo PSDB, PMDB, PFL e PT, foram responsáveis por $184(63 \%)$ inscrições. Tais dados coincidem com a presença desses partidos no cenário político nacional e refletem, por exemplo, a divisão de forças nas casas legislativas federais. Tanto no Senado como na Câmara dos Deputados, PFL, PMDB, PSDB e PT, formam, respectivamente, as maiores 'ancadas de parlamentares.

Por fim, é importante destacar que apesar de alguns programas e projetos inovadores estarem fortemente identificados em sua origem a determinados partidos, é possível encontrar programas inovadores tanto em municípios dirigidos pelo PFL como pelo PT, como também existem programas de modernização da gestão pública, e voltados para a inclusão social, que foram formulados por gestores filiados aos mais diversos partidos.

\section{Bibliografia consultada}

BELTRÃO, Ricardo Ernesto Vasquez; FARAH, Marta Ferreira Santos \& LACZYNSKI, Patrícia. "Um primeiro olhar sobre o Ciclo de Premiação 1998". In: BELTRÃO, Ricardo Ernesto Vasquez; MAURO, Carlos Eduardo Evangelisti \& LACZYNSKI, Patrícia (org.). Cadernos Gestão Pública e Cidadania (A administração pública brasileira inovando a forma de governar: apresentação dos 631 programas inscritos no Ciclo de Premiação 1998). São Paulo: EAESP-FGV, v.12, 1998, p.7-19.

FARAH, Marta Ferreira Santos. Governo Local, Políticas Públicas e Novas Formas de Gestão Pública no Brasil . Organizações e Sociedade, Salvador: v.7, n. 17, jan./abr.2000, p.59-86.

FARAH, Marta Ferreira Santos \& BELTRÃO, Ricardo Ernesto Vasquez. "Perfil dos programas inscritos em 1997". In: BELTRÃO, Ricardo Ernesto Vasquez (org.). Cadernos Gestão Pública e Cidadania (A administração pública brasileira inovando a forma de governar: apresentação dos 297 programas inscritos no Ciclo de Premiação 1997). São Paulo: EAESP-FGV, v.8, 1996, p.7-14.

FARAH, Marta Ferreira Santos. "Que está mudando na gestão pública brasileira? Tendências sugeridas pelos programas inscritos". In: BELTRÃO, Ricardo Ernesto Vasquez (org.). Cadernos Gestão Pública e Cidadania (A administração pública brasileira inovando a forma de governar - Ciclo de Premiação 1996). São Paulo: EAESP-FGV, v.1, 1996, p.7-16.

FUNDAÇÃO INSTITUTO BRASILEIRO DE GEOGRAFIA E ESTATISTIICA - IBGE. CenSo Demográfico 2000. Rio de Janeiro: IBGE, 2001.

LACZYNSKI, Patrícia, BELTRÃO, Ricardo Enesto Vasquez \& FARAH, Marta Ferreira Santos. "Uma breve análise do Ciclo de Premiação 1999". In: LACZYNSKI, Patrícia., BARACCHINI, Sabrina Addison \& BELTRÃO, Ricardo Ernesto Vasquez (org.). 
Cadernos Gestão Pública e Cidadania (A administração pública brasileira inovando a forma de governar: apresentação dos 888 programas inscritos no Ciclo de Premiação 1999). São Paulo: EAESP-FGV, v.16, 1999, p.7-16.

LACZYNSKI, Patrícia; AROUCA, Francine Lemos \& FUJIWARA, Luis Mário. "O que há de novo no Programa Gestão Pública e Cidadania". In: PETER, Spink; LACZYNSKI, Patrícia \& AROUCA, Francine Lemos (orgs.). A administração pública brasileira inovando a forma de governar: apresentação dos 728 programas inscritos no Ciclo de Premiação 2001. São Paulo: EAESP-FGV, v.21, 2001, p.7-17.

SPINK, Peter. The Rights Approach to Local Public Management: experiences from Brazil. Revista de Administração de Empresas. São Paulo: v.40, n.3, jul./set.2000, p.45-65.

SPINK, Peter. Gestão Municipal faz escola: aprendendo com os governos locais. Cadernos Adenauer. os municípios e as eleições de 2000. São Paulo: n.4, jun.2000.

SPINK, Peter; CLEMENTE, Roberta \& KEPPKE, Rosane. Governo local: o mito e as novas práticas de governança. Revista de Administração. São Paulo: v.34, n.1, jan./mar.1999, p.61-9. 